\title{
A PERCEPÇÃO DOS PARLAMENTARES POTIGUARES ACERCA DO LOBBYE DO PODER DE INFLUÊNCIA DOS GRUPOS DE PRESSÃO
}

\section{PERCEPTION OF THE POTIGUARES PARLIAMENTARY ABOUT THE LOBBY} AND THE POWER OF INFLUENCE OF THE PRESSURE GROUPS

\section{César Ricardo Maia Vasconcelos}

Doutor em Administração (Ph.D) pela Université Pierre Mendes (Grenoble/

France). Professor permanente dos Programas de Mestrado e Doutorado Acadêmico em Administração da Universidade Potiguar (Natal/Brasil).

Gabriel Lacerda de Paula

Mestre em Administração pela Universidade Potiguar (Natal/Brasil). 


\section{RESUMO}

O presente artigo de discussão teórica tem por finalidade abordar estudos relacionados à atividade de influência proveniente do Lobby e dos Grupos de Pressão. Para tanto, foram analisados, essencialmente, artigos de periódicos clássicos sobre a matéria, com publicações reconhecidas internacionalmente, disponiveis em bases de pesquisas especializadas, ocorridas no período de 1963 a 2016. De paradigma construtivista e associado à abordagem qualitativa, este trabalho, baseado nas investigações iniciais e lastreado por estudos específicos, permite concluir, preliminarmente, que as atividades dos grupos de pressão e de lobby se apresentam como vitais para obter vantagens hipercompetitivas mediante intervenção direta, seja nas decisões dos agentes públicos, seja na elaboração de legislações específicas.

Palauras-chave: Lobby. Grupos de Pressão. Poder de Influência. Agentes públicos. Políticas públicas.

\section{ABSTRACT}

The present article of theoretical discussion has as purpose to approach studies related to influence activity from Lobby and Pressure Groups. In order to do so, we have analyzed, essentially, articles from classic journals on the subject, with internationally recognized publications, available on specialized research bases, from 1963 to 2016. From a constructivist paradigm associated to the qualitative approach, this work, based on the initial investigations and backed up by specific studies, it is possible to conclude preliminarily that lobbying and lobbying activities are vital for obtaining hypercompetitive advantages through direct intervention in the decisions of public agents and in the elaboration of specific legislations. Keywords: Lobby. Power of Influence. Peer Pressure. Public Agents. Public policy. 


\section{INTRODUÇÃO}

Este artigo consiste de investigações originadas a partir de uma revisão da literatura pertinente à atividade de influência do Lobby e dos Grupos de Pressão. Neste contexto, construir um quadro teórico é meritório. Para Argyris (1995, p. 306), "a teoria é reconfortante, ela permite reduzir a incerteza, 'colocar ordem na desordem aparente'".

O termo Lobby, em seu sentido literal, originário da língua inglesa, pode assumir os seguintes significados: sala de espera, antessala ou hall. Porém, o mesmo passou a ser utilizado para representar o que acontece nesses locais e não mais apenas num espaço físico qualquer. 0 termo ganhou uma conotação diferente desse sentido em casas legislativas. Isto ocorreu pela forma como os representantes de grupos de interesses organizados atuavam juntamente aos parlamentares, em tais espaços, para conversar e tentar influenciá-los sobre determinada matéria do interesse do seu grupo. Para Libardi (2012), este termo é entendido como uma atividade que insere a prática da influência no contexto das decisões políticas no intuito de resguardar ou alcançar determinado interesse. Com efeito, é exatamente o local em que acontece esta atividade de influenciar o legislador que transformou esta acepção de espaço físico em atividade profissional de persuasão.

Muitos pesquisadores discutem onde surgiu o lobby. Para Romagni (1994), este surgiu nas câmaras legislativas da Inglaterra há mais de um século, pela atuação de grupos de interesses que procuravam influenciar as decisões do parlamento. Já Oliveira (2004) sustenta que o lobby nasceu nos Estados Unidos da América e o entende como um processo em que os grupos de pressão procuram participar do sistema de tomada de decisões do governo, agregando informações para a construção das políticas públicas. É neste contexto levantado por Oliveira (2004) que surge o entendimento de que o lobby é muito mais do que apenas uma atividade isolada de um determinado grupo; ele aparece também como instrumento democrático a ser utilizado pela sociedade na defesa dos seus interesses, reforçando a ideia de sustentação do processo democrático de um país. Este entendimento é asseverado por Romagni (1994), quando pontua que o lobbynasceu nos interstícios da democracia e que toda e qualquer atividade do poder público vai buscar a sua legitimidade no atendimento do interesse geral. Na mesma linha de raciocínio, Soimu, Margarit, Andrisan e Stefan (2011) afirmam que o lobby é um mecanismo democrático por proporcionar aos seus atores a possibilidade de se envolverem e participarem do processo decisório estatal.

O lobby não representa, por si só, uma pressão em aprovar ou defender determinada matéria perante o poder público, já que este tem o princípio de trazer consigo um conjunto de informações específicas que o legislador ainda ignora. Scott (2015) aborda que o lobby é distinto do ato de fazer uma contribuição para uma campanha ou um candidato, pois enquanto as doações podem facilitar o acesso ao 
parlamentar, a verdadeira influência proveniente da atividade do lobby vem de relações estabelecidas em ambientes diversos. Observa-se, ainda, que um lobista exerce influência junto aos legisladores fornecendo informações diferenciadas, por vezes conhecidas como informação cinza, ou seja, informações informais carentes ainda de validação (VASCONCELOS, 1999).

\section{LOBBY}

A atividade de lobby pode ser entendida como um encadeamento lógico de ações que envolvem a busca de informações especiais e de métodos qualificados para o atendimento dos interesses de grupos organizados. Estas atividades encadeadas são executadas por grupos de pressão que oferecem informações seguras e precisas aos tomadores de decisão e estes os transformam em parceiros, convidando-os a opinarem quando necessário. Estes grupos praticam o lobby para influenciar o legislador ou a autoridade pública acerca das decisões de interesse comum. Dessa forma, o lobby, na opinião de Oliveira (2004), pode ser considerado como informação privilegiada acessivel para fomentar a tomada de decisão.

Hall e Deardorff (2006) abordam o lobby como sendo um subsídio legislativo. Consideram que os lobistas fornecem informações de alto valor para legisladores criteriosamente selecionados de pensamentos alinhados com os seus na busca de apoio a objetivos políticos compartilhados. Ressaltam ainda que não se trata necessariamente de mudar a mente dos políticos, mas de fomentá-los com estas informações para atingir estes objetivos.

Mack (2005) releva o conceito de lobby nas perspectivas presentes na lei dos EUA e do Parlamento Europeu e o aduz como o ato de entrar em contato com políticos ou autoridades públicas no intuito de influenciar decisões pertinentes aos seus interesses. Já Mayrhofer (2014), ao considerar que os grupos de interesse e de pressão são os principais influenciadores europeus, expressa que o lobby corresponde às ações de promoção, representação e defesa de interesses por intermédio da influência no processo decisório político.

Graziano (1994), em um estudo que analisa o lobbyno cenário político americano, compreende que a atividade lobista atua em uma conjuntura que deriva de uma gama de interesses diversificados e que, em várias situações, tornam-se necessários conhecimentos específicos sobre determinada matéria. Logo, o considera como um suporte técnico para a representação de interesses, uma vez que os lobistas ou grupos de pressão aparecem como portadores de uma informação especializada capaz de maximizar a influência em uma decisão política. Rasmussen (2015) acrescenta que o conhecimento técnico proporcionado pelos interessados é necessário para permitir que o legislador faça uma avaliação crítica das matérias sob sua apreciação. Termina por ser um apoio mútuo, em que o interesse do grupo tende a ser deferido e 
o legislador amplia o seu conhecimento sobre o tema e entende melhor do assunto por ser servido de informações especializadas de difícil acesso, isto é, valer-se de informações tidas como privilegiadas.

Para Libardi (2012), o Lobby é tido como uma atividade que pretende interferir ou influenciar o processo decisório estatal em defesa de interesses específicos, configurando-se como uma ferramenta essencial para entidades democráticas e para a participação da sociedade nas tomadas de decisões governamentais. Ressalta que é na lacuna do conhecimento do homem público que o lobby cria valor. Em síntese, o lobby almeja o encaminhamento de decisões que interessam ou de qualquer forma favorecem certo grupo da sociedade. Mostra-se como uma atividade de convencimento que é praticada através do provimento e da troca de informações e proposições políticas entre o poder público e o operador do lobby.

Romagni (1994), no que lhe diz respeito, aduz que o lobby é o resultado da organização de grupos bem definidos e solidários que pretendem fazer representar os interesses alinhados à intenção daqueles que os representam. Rival (2006), por seu turno, define o lobby como uma atividade realizada por meio de intervenções dos interessados no intuito de influenciar, direta ou indiretamente, o processo de desenvolvimento, aplicação ou interpretação de legislações, normas e regulamentos, como também em decisões governamentais.

Já Polère (2007) descreve o lobby como a atividade de influenciar decisores políticos por meio de um grupo de interesse. Este autor afirma que o lobby tem como objetivo principal influenciar o poder legislativo e que o mesmo é uma atividade política que não se restringe à atuação de grupos econômicos, mas diz respeito tanto a estes grupos como aos de interesse público, através das ONG's e demais classes sociais. Para Farhat (2007), é compreendido como atividade praticada dentro da lei e de preceitos éticos por grupos de interesses especiais e legítimos que tem por finalidade se fazer ouvido pelo governo com o propósito de obter benefícios ou facilidades através de medidas, decisões e atitudes amparadas nos princípios deontológicos.

Faz-se importante abordar que, em seu estudo, Libardi (2012) classifica o lobby como sendo direto ou indireto. O primeiro se constitui dos contatos pessoais e das trocas de informações e tem o intuito de esclarecer as situações sobre as quais recairão a possivel decisão política que vai interessar determinado grupo; percebe-se aqui, novamente, a importância de uma informação especializada e de acesso restrito. Já o lobby indireto é encontrado como sendo aquele praticado por grandes grupos econômicos ou de representação social, que atuam por meio das pressões provenientes de grandes esforços e mobilizações.

A classificação de lobby direto de Libardi (2012) assemelha-se com o que Polère (2007) chama de atividade de lobby interno, que é o lobby direto através de contatos com as pessoas para influenciar autoridades governamentais, parlamentares e funcionários do governo envolvidos nos processos legislativos que afetam os seus interesses. 
Na esteira de que o lobby precisa atuar com a sua influência no momento e no lugar exato, Romagni (1994) trata dos níveis de intervenção do lobby, momento em que o conceitua como defensivo e ofensivo. No tocante ao nivel defensivo, coloca como sendo aquele que objetiva assegurar a defesa da causa ou

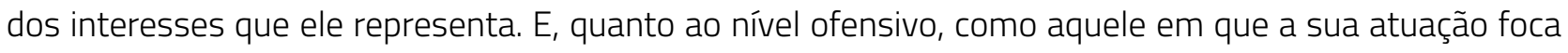
na informação e na sugestão de alianças estratégicas ou parcerias para obter o que almeja. Nestes dois níveis abordados pelo autor, este destaca que não se pode distanciar da qualidade das informações.

Já Farhat (2007) vê o lobby em sentido restrito e em sentido amplo. O primeiro é visto como a prática de influenciar as decisões públicas através de agentes que servem a interesses de algum grupo, com o fito de levar autoridades a fazer, ou não, alguma coisa a bem daqueles interesses. E em sentido amplo, como aquele que indica todo o esforço desprendido, através de quaisquer meios legais, incluindo os de comunicação, voltado a influenciar a tomada de decisões do governo.

\section{GRUPOS DE PRESSÃO}

A questão de formação de grupos de indivíduos vem se apresentando como ponto central de muitos estudos organizacionais e da sociedade em geral. Percebe-se que, tanto em organizações como no convívio social, a junção de pessoas pode ocorrer de forma natural, por simples identificação dos membros, ou intencional, na busca por algum objetivo. Kalkhoff e Barnum (2000) enfatizam que uma pessoa considerada como pertencente a determinado grupo possui mais influência do que outra que não está inserida. Destacam que a combinação de ser membro com as características de status de um grupo afeta o seu desempenho como influenciador. Realçam este entendimento os autores Lovaglia e Houser (1996) e Lucas e Baxter (2012) ao tratarem da relevância das percepções de status envolvendo grupos no sentido do desempenho da atividade de influência.

Becker (1983) pontua que indivíduos pertencem a determinados grupos que podem ser definidos como empresarial, de renda, geográfico, pela idade, pelo sexo, pelos costumes de consumo, entre outros, e que assumem uma postura de usar a influência política para melhorar o bem-estar de seus membros. O autor assevera que esta influência política é resultante do lobby e que em todas as sociedades existem praticamente um número ilimitado de grupos de pressão que se formam para propiciar benefícios políticos aos seus membros. Já Smith (1989) aborda que quase todos os segmentos da sociedade são representados por algum grupo, dentre eles os chamados "grupos de pressão". Por sua vez, Whawell (1998) notabiliza que estes grupos possuem um papel vital na consecução do equilíbrio entre o alcance do objetivo do grupo e dos direitos presentes na sociedade. 
Para Mckinney e Halpin (2007), a rotulagem de um grupo como sendo especificamente de pressão é proveniente das avaliações que são feitas a seu respeito considerando o seu status e a sua importância na política global. No que Ihe diz respeito, Mackley (2011) mostra que é admirável o entendimento dos grupos de pressão, pois o parlamento é o responsável pela elaboração de legislações, mas torna-se ingênuo acreditar que estes grupos não são, pelo menos parcialmente, responsáveis pelas mudanças e ou complementações de matérias legais.

Com efeito, destaca-se a pertinência em conhecer a simbiose existente entre grupos de pressão e os denominados grupos de interesse. Nesta perspectiva, Beard (1969) evidencia que os grupos de pressão são aqueles que operam o lobby através de membros selecionados do parlamento, que podem ou não empregar esforços mais contundentes para atingirem seus objetivos. Já Smith (1989) aborda que os grupos de pressão são componentes integrantes do tecido da sociedade e do processo político, funcionando como um circuito auxiliar de representação. Estes grupos são formados para promover os interesses de um conjunto de indivíduos ou para obter o apoio de um ponto de vista, e utiliza uma variedade de caminhos para influenciar situações por meio da opinião pública, dos executivos ou do governo.

Aragão (1994) parte do pressuposto de que um grupo de interesse é o estado inicial ou originário de um grupo de pressão e que a forte atuação em atividade de influência é o que determina a diferenciação entre estes grupos. $\mathrm{O}$ autor realça que todo grupo de pressão é um grupo de interesse e que este último se transforma no primeiro no momento em que pressiona o processo decisório. Güney (2015) ratifica este entendimento quando considera que no momento em que os grupos de interesses especiais agem de forma organizada eles se configuram como grupos de pressão.

Para Farhat (2007), grupo de interesse é todo conjunto de indivíduos organizados sob qualquer formato legal, em que se identifica uma convergência de anseios, intenções e objetivos em torno de determinada matéria. Já o grupo de pressão é o grupo de interesse no momento em que ele muda de postura passando a atuar na busca das suas cobiças com os meios necessários. E, na visão de Sinha (2012), esses grupos são aqueles que se esforçam para assegurar determinado interesse por influenciar a formulação e a administração de políticas públicas. Eles não estão atrelados a partidos políticos e trabalham como um grupo de atuação indireta e poderosa para interferir na decisão política.

Epstein, Mealem e Nitzan (2013) evidenciam que um grupo de interesse é formado para interferir no processo decisório com o fito de influenciar uma decisão final dos parlamentares do poder legislativo. Aduzem que, para lograr êxito nas suas intenções perante os representantes do referido poder, o grupo depende da proximidade de um partido ideologicamente semelhante, para que seja agregada força e lastreada a sua demanda. Neste mesmo princípio, Rana (2014) destaca a relevância do papel dos grupos de pressão para fomentar e complementar a função das atividades dos partidos políticos. Pontua que 
estes compõem o processo político de forma abrangente, ao mesmo tempo em que os primeiros procuram influenciar as decisões políticas sem estarem inseridos no processo formalmente. A autora ainda salienta que um grupo de pressão atua na perspectiva de interferir no agir dos legisladores concedendo informações e utilizando mecanismos para isso. Aborda que o grupo de pressão é derivado do grupo de interesse e que a transformação ocorre no momento em que o segundo passa a utilizar a estratégia da persuasão sobre os representantes públicos.

\section{INFLUÊNCIA}

A influência e as suas relações estão presentes na sociedade e em seus diversos contextos. Vários estudos foram realizados acerca do tema na tentativa de entender como ela se apresenta e qual a sua relação e possível similaridade com o poder. A literatura técnica mostra que existe uma delimitação entre os seus conceitos e que, apesar de serem vistos muitas vezes como sinônimos, é possivel delimitá-los separadamente sem que se exclua a relação existente entre os dois.

Parsons (1963) abordou que a influência se apresenta como um meio de persuasão e que ela tem o objetivo de provocar uma decisão por parte da pessoa influenciada. A mesma procura fazer com que o influenciado aja de uma determinada maneira, absorvendo o sentimento de que aquela decisão é algo positivo pelo fato de alguém tê-lo feito enxergar que possui boas razões para isso, independentemente de qualquer obrigação que tenha de tomá-la. Já em uma situação de poder, a decisão parte de uma referência de autorização, no sentido de que essa decisão deva ser tomada dentro de certos limites e sem margem para julgá-la como atitude positiva para proveito próprio, ou seja, toma decisões voltadas aos interesses da coletividade. Neste caso, o autor considera que as decisões partem de obrigações e destaca a importância de se dar razões ou justificativas para que o influenciado siga determinada linha de ação, pois, para influenciar, é necessário que haja a justificação das intenções do influenciador. Ademais, o usuário de influência precisa fundamentar as suas declarações que se destinam a ter um efeito sobre as atitudes do outro, fazendo com que correspondam às expectativas da parte influenciada, que são consideradas como vinculativas para as ações orientadas com base naquilo que é objeto da influência. Dummert (2013) corrobora este entendimento ao afirmar que, para que se possa influenciar, tem que ser dado às pessoas uma razão para ser ouvido. Depois, é preciso convencê-las de que é importante que elas a ouçam e que se sintam próximas, pois as mesmas tendem a ser influenciadas por aqueles que se mostram em estreita proximidade com elas.

Willer, Lovaglia e Markovsky (1997) consideram que as concepções de poder e influência são importantes para que se compreenda a vida em comunidade. Destacam a importância da separação dos 
conceitos, mas também consideram que existe uma estreita relação entre os mesmos e que um pode interferir no outro. Os autores definem o poder como sendo um potencial estruturalmente definido para a obtenção de retornos favoráveis nas relações em que os interesses das partes são opostos. Consideram que é a posição do executivo que lhe dá poder sobre o empregado, em vez de ser algo que seja intrínseco à pessoa que ocupa a posição superior. Já com relação à influência, definem como sendo uma modificação socialmente induzida de uma crença, atitude ou expectativa, alcançada sem a utilização do recurso de aplicação de sanções. Percebe-se, no estudo, que as expectativas não precisam ser necessariamente reconhecidas por aqueles que as detêm; para detectar influência, basta que se observe a mudança de comportamento sem o receio de sofrer qualquer penalidade, e ela passa a ocorrer quando os envolvidos mudam os seus comportamentos porque eles entendem que a mudança pode beneficiá-los diretamente ou ao grupo a que pertencem. Os autores seguem a descrever os conceitos como sendo distintos, mas sem deixar de compreendê-los como fenômenos relacionados. Desenvolvem as suas argumentações em torno da importância de tal distinção afirmando que a mesma é complexa e deixam a margem de que, mesmo sendo diferentes, o poder pode ser confundido com a influência dependendo das reações emocionais que provocam naqueles que estão passiveis destas situações.

Neste sentido das reações emocionais, Lovaglia e Houser (1996) publicaram uma pesquisa que envolve quatro estudos relacionados com as reações emocionais ligadas às emoções que os participantes sentem em relação à influência. 0 estudo mostra que as emoções negativas percebidas pela parte influenciada provenientes da tentativa de influência aumentam a sua resistência a mesma. E que as emoções positivas provocadas pela parte que influencia geram a diminuição da resistência de ser influenciado. Os autores ressaltam que os efeitos provocados pelas emoções combinados com os efeitos de informações de status que a parte influenciada percebe da outra ajuda ainda mais na obtenção de resultados benéficos para o grupo de trabalho, ou seja, um conjunto de emoções positivas aliadas à percepção positiva do status do influenciador, em relação a uma pessoa ou ao grupo, tende a gerar bons resultados. Os escritores refletem sobre o assunto porque, para eles, a combinação dos efeitos de emoções com as de características de status do influenciador, pode acarretar na possibilidade de gerenciamento das emoções dos outros para que se tenha sempre um bom nível de influência sobre as decisões do grupo em ambientes de trabalho. Esta ação tem o potencial de mitigar alguns efeitos negativos provenientes de possivieis percepções acerca de determinada tentativa de influência e de buscar sempre a canalização de esforços para provocar atitudes positivas que podem gerar bons frutos para o grupo de trabalho. Aproximando-se os conceitos e considerando a importância de gerenciar a influência na arena política, Meyer (2012) reforça esse entendimento ao frisar a necessidade desse gerenciamento para que se possa influenciar as partes interessadas e se interfira no processo decisório político. 
Para Lucas e Baxter (2012), o poder é considerado como a capacidade de impor a própria vontade mesmo contra a vontade ou resistência dos outros. Ele é produto da posição de uma pessoa em relação a outra em uma estrutura social. Já a influência, os autores consideram como sendo uma mudança de comportamento de forma convincente, sem a promessa de recompensa e com a ausência de ameaças de possíveis punições. Para eles, a mesma resulta, em grande parte, do respeito e da estima que uma parte possui pela outra. A pesquisa de Lucas e Baxter (2012) também identificou a questão do status na relação de influência dentro de grupos, percebendo o potencial de influência de membros benquistos dentro de determinados grupos. Na mesma linha dos autores Lucas e Baxter (2012), que abordam a influência como sendo uma forma de mudança de comportamento convincente, Sell et al. (2004) esclarecem que ocorre uma situação de influência no momento em que as pessoas passam a desenvolver certas condutas porque foram convencidas de que estas são as atitudes certas a serem realizadas, e não porque alguém com poder impôs que devessem acontecer.

Dummert (2013) considera a influência como sendo uma ideia que é passada de uma pessoa para outra. Para o autor, o ponto chave para influenciar está no fato de saber se posicionar estrategicamente em relação aos outros e compreender quais são os objetivos comuns existentes entre aquilo que se quer com os que a outra parte também deseja, e saber encaixar esses objetivos no momento certo para transformar a influência em movimento de interesse comum. Trata-se de assumir uma posição para acrescentar algum valor ao outro e transformar isso em atitude. Dummert (2013) pontua que a influência gera resultados melhores quando começa de uma forma gradual, em que pequenas mudanças vão gerando oportunidades para outras novas e mais profundas.

Já Barnes (2014) afirma que a influência acontece na mente da outra pessoa e que para influenciá-la é necessário tempo para aprender sobre ela. Para o autor, faz-se necessário que o influenciador se coloque no lugar da outra parte para criar uma situação de intervenção a partir de uma ideia ou proposição que faça sentido para ela e esteja dentro da sua visão de mundo. Barnes (2014) ressalta que é importante que se esteja disposto a enquadrar as suas ações como algo que aparente ser razoável para a outra pessoa, mantendo, ao mesmo tempo, a sua própria essência. Percebe-se que, na visão do autor, existe uma relevância no fato de se enquadrar à realidade da outra parte, e isso inclui a necessidade de se considerar o contexto em que a parte influenciada atua.

O estudo de Chong, Fu e Shang (2013) trouxe a abordagem do poder relacional e a sua interferência na escolha de determinada estratégia de influência. Eles buscam entender como uma pessoa sem posição ou poder pessoal consegue convencer outras pessoas a cumprirem uma solicitação de tarefa de trabalho, enquanto uma outra com estas condições não obtém o mesmo resultado ao fazer um pedido semelhante. Para os autores, o poder relacional pode ser compreendido como um poder informal decorrente das relações 
pessoais das partes envolvidas. Destacam que este poder, para ser caracterizado, precisa ser interativo e que, caso não seja feito um esforço pelas partes para que seja criado um bom relacionamento, o mesmo não existirá. Os resultados do estudo evidenciam o poder relacional como uma fonte de poder diferente, que não só impacta nas escolhas gerenciais acerca do uso de estratégias de influência mais apropriadas para a ocasião, mas também sua eficácia sobre a pessoa objeto da influência. Estes resultados fornecem implicações para as relações do cotidiano das organizações, pois, ao tratarem da existência desse poder, mostram que os gerentes devem reconhecer os seus efeitos e a sua relação com os diferentes tipos de estratégias de influência para que possam desenvolvê-lo e utilizá-lo da melhor forma possivel. Torna-se prudente ressaltar que o estudo identifica a existência de uma relação negativa entre o poder de posição e a estratégia de influência persuasiva, particularmente quando os influenciados são os trabalhadores da linha de frente da organização.

Ressalta-se, ainda, que os autores Chong, Fu e Shang (2013) consideram que o poder relacional tem a característica de ser neutro - quando é utilizado para gerar efeitos bons é mais provável que gere resultados positivos. Porém, se ele for usado sem boas intenções, pode gerar mais danos do que os outros dois tipos de fontes de poder por causa do envolvimento de emoções. Neste ponto, os autores encontram congruência com o já citado estudo de Lovaglia e Houser (1996), que abordou que o envolvimento de emoções positivas ou negativas pode gerar um efeito de resistência ou não à influência, implicando na efetividade do resultado da intenção de interferir nas atitudes e ações dos outros. Encaixa-se nesse entendimento dos autores a observação de Rival (2006), que salienta que a influência proveniente do lobby se torna mais convincente quando gera externalidades sociais positivas.

Reber e Berger (2006) definem influência como sendo a capacidade de realizar coisas por afetar as percepções, atitudes, crenças, opiniões, decisões, declarações e comportamentos de outras pessoas e, em nível organizacional, como a capacidade de impactar os planos estratégicos da empresa e a sua direção geral, bem como as suas metas e objetivos. Ademais, os autores realizaram um estudo que teve por objetivo analisar a influência dos profissionais de relações públicas em organizações e identificaram que para se tornarem membros dos órgãos de tomada de decisão os mesmos devem exercer influência. Além disso, uma vez membros de tais grupos, estes profissionais devem usar táticas e estratégias de influência para ajudar nas decisões e nas ações da organização. Dentre os achados da pesquisa está a definição de que a influência é o poder de persuadir e convencer o outro a decidir ou realizar ações sem que necessariamente se tenha autoridade para isto, e que se deve utilizar de meios para que os argumentos sejam ouvidos e a voz seja repercutida em interferência no agir do outro. Estes achados alinham-se com os estudos de Sell et al. (2004) e Lucas e Baxter (2012), já citados, no tocante ao reconhecimento de que uma situação de influência é proveniente de um processo de convencimento, no qual a parte influenciada 
aceita aqueles argumentos e se sente motivada a tomar decisões ou a desenvolver ações propostas pela outra parte.

\section{TIPOS, ESTILOS, ESTRATÉGIAS, HABILIDADES, DIMENSÕES E PRINCÍPIOS DA INFLUÊNCIA}

Considerando a relevância da "influência" e suas variáveis na obtenção de vantagens competitivas, torna-se apropriado abordar as diferentes percepções, classificações ou nomenclaturas disponíveis na relacionada literatura.

Manning (2012a, 2012b) publicou estudos envolvendo estratégias e estilos de influência e abordagem das habilidades em situações de influência. No primeiro estudo, evidenciou que os indivíduos utilizam seis estratégias para influenciar terceiros de acordo com o contexto em que está inserido no momento. Para ele, estas são as seis estratégias utilizadas: Razão; Afirmação; Troca; Cortesia; Coerção; Parceria. Segundo o autor, a combinação de uso dessas estratégias pelo influenciador define o seu estilo de atuação perante as outras pessoas. Com base neste posicionamento, Manning (2012a) chegou aos seguintes estilos: Espectador-Atirador; estrategista-oportunista; colaborador-batalhador.

Posteriormente, Manning (2012b) elenca sete habilidades que o influenciador precisa dominar para que possa ser bem-sucedido na tentativa de influência. O mesmo as identifica como: ser claro sobre "quem", "o quê" e "porquê"; saber direcionar o que quer sobre a outra pessoa; procurar um terreno comum entre as partes; manter-se simples; saber a hora de apelar à cabeça e ao coração; ser calmo e confiante e ser interativo.

Kipnis, Schmidt e Wilkinson (1980), sobre outro enfoque, obtiveram como resultado dos seus estudos o que eles chamaram de dimensões de influência. Para os autores, a influência possui oito dimensões, assim classificadas: bajulação, racionalidade, assertividade, sanções, troca, apelo para cima, bloqueio e coligações; e as relacionaram com as situações de influência quando se tem por objetivo influenciar superiores, pares e subordinados.

Já Reber e Berger (2006, op. cit.) associaram o papel da influência à prática de relações públicas, oportunidade em que fizeram a proposição de princípios para que se influencie quando se está à frente das suas condutas profissionais, são eles: para ter influência em relações públicas é preciso ter um papel na tomada de decisões e nas ações da organização; para ter influência em relações públicas é preciso ter acesso e a atenção da gerência sênior; para ter influência em relações públicas é preciso praticar efetivamente a arte da persuasão; profissionais de relações públicas são mais influentes quando as organizações enfrentam crises; profissionais de relações públicas são mais influentes na elaboração de mensagens institucionais; profissionais de relações públicas não têm influência na tomada de decisões 
estratégicas; profissionais de relações públicas não têm influência quando eles são vistos como técnicos; as táticas de influência mais eficazes dos profissionais de relações públicas, ao tentar influenciar a gestão da sua organização, são: a racionalidade, a construção de coalizões, a pressão, a experiência e os recursos de inspiração.

Por seu turno, Parsons (1963) considera que é necessário ter em mente que a influência não é um sistema fechado, e que para obter o consentimento de alguém o influenciador deve compreender as ocasiões em que está inserido e ter a percepção exata de quando e como vai intervir. Para isso, sugere a existência de quatro tipos de influência: a influência política, a influência fiduciária, a influência através de apelo ao diferencial de lealdades e a influência orientada para a interpretação das normas; com ênfase para a influência política. $O$ autor concebe este tipo de influência como sendo a que opera no contexto que tem por meta o funcionamento das coletividades e que se utiliza da persuasão de forma generalizada, ou seja, na incidência da mesma sem o uso de ameaça ou de poder direto, embora não descarte a existência de uma relação entre os dois.

\section{INFLUÊNCIA POLÍTICA E O LOBBYDOS INTERESSES ORGANIZADOS}

A influência política se apresenta como fator relevante no contexto das organizações e dos interesses organizados. Saber lidar com os diversos instrumentos e mecanismos, bem como o momento correto de ação dentro do âmbito político pode ser um diferencial para obter as mudanças desejadas.

Marshall (2010) publicou um estudo na tentativa de compreender a interface institucional entre os parlamentares e as atividades de interesses organizados no Parlamento Europeu. 0 autor percebe que os procedimentos formais do parlamento e a sua organização informal determinam a forma como é distribuída o que ele denomina de influência legislativa entre os deputados e, por consequência, o posicionamento estratégico dos operadores de lobby. O estudo aborda que o principal objetivo do lobby dentro do Parlamento é a influência por meio da negociação de interesses, que é caracterizado através de um processo bem-sucedido de obtenção de um relatório legislativo favorável.

Para obtenção deste relatório, Marshall (2010) salienta que é essencial para os lobistas saberem decidir corretamente sobre qual legislador ou legisladores devem concentrar as suas atividades de lobby, e em que momento do processo legislativo isto deve ocorrer. Para tanto, é importante o conhecimento das regras formais, pois elas fornecem uma lógica temporal de como ocorre a tramitação de um relatório dentro de uma comissão, dividindo o processo legislativo em fases. Isso proporciona, para os interessados, oportunidades distintas de influenciar de acordo com a evolução do processo. Fica caracterizado, no estudo, que a fase aberta para alterações, onde os membros da comissão e outros deputados são livres para 
apresentar emendas, é o momento oportuno para que os influenciadores assumam um comportamento estratégico entre os membros da comissão e estruturem as suas atividades de lobby.

Em outra análise, Marshall (2015) aprofunda suas pesquisas e, além de ratificar que o objetivo dos interesses organizados é o de influenciar os resultados das políticas, acrescenta que é mais oportuno pressionar os parlamentares que possuem interesses alinhados aos seus para maximizar o potencial explicativo das informações que desejam inserir em legislações e alavancar a sua influência legislativa. Assim, eleva a influência a um nível em que ela se apresente de forma estratégica, proporcionando aos grupos aguçarem o seu instinto de reconhecer as intenções de voto e aproxima os legisladores para a sua posição política. Nesta mesma linha de influência política no cenário do Parlamento Europeu, Rasmussen (2015) busca identificar as condições sob as quais grupos empresariais moldam resultados políticos neste parlamento e aborda que a capacidade das empresas de deixarem as suas impressões digitais nos relatórios das comissões depende de um conjunto de fatores.

A pesquisa evidencia que o referido parlamento é visto como um local propício para a representação de interesses difusos, mas que os parlamentares estão abrindo cada vez mais espaço para as questões empresarias em detrimento dos interesses da coletividade. 0 estudo analisa quatro situações em que foram travadas batalhas entre interesses de grupos empresariais e de grupos defensores de interesses de abrangência coletiva. Nas duas situações em que a necessidade de informações precisas e especializadas se mostraram mais evidentes, como no caso da regulamentação sobre informações alimentares aos consumidores nos produtos e no caso da redução da emissão de $\mathrm{CO}_{2}$ de veículos tipo van, os anseios dos negócios prevaleceram. E nas outras situações que tratavam dos direitos das trabalhadoras grávidas e do tempo de jornada de trabalho no transporte rodoviário, os sindicatos tiveram seus pontos de vista atendidos. Faz-se oportuno abordar o que ressalta Chalmers (2013) ao evidenciar que grupos dotados de informações especiais se posicionam melhor perante os parlamentares europeus por fornecerem informações que são necessárias aos mesmos e, assim, influenciam o processo decisório de determinada matéria.

Além disto, fica evidenciado, na opinião de Rasmussen (2015), que três aspectos são fundamentais para que a influência seja realizada com sucesso por grupos empresariais: a unidade de negócios, a baixa repercussão da matéria e os relatórios sendo tratados pelas comissões principais. A unidade interna dos grupos de negócios se apresenta como um pré-requisito para que eles possam influenciar a política, como por exemplo na regulamentação de informações alimentares aos consumidores e de redução de emissão de CO2 de vans, em que os deputados foram expostos, principalmente, à pressão de grupos empresariais que se uniram e obtiveram uma participação nos resultados dos relatórios. Este primeiro aspecto citado assemelhasse com o que é argumentado por Bunea (2015), que aborda a importância da aliança formal 
dos interesses organizados para que seja criada uma convergência de tais interesses e que se formem coalizões de lobby entre grupos de interesse para que os seus propósitos estejam sempre alinhados. E, defendido por Rival (2012), quando trata dos benefícios que podem ser provenientes de ações coletivas de lobby, como ganho de influência e credibilidade em negociações, aumento da capacidade de enfrentar lobby adversário, competitividade e sinergia.

No que tange à repercussão da matéria, os interesses dos negócios tendem a ser atendidos quando essa não possui visibilidade expressiva da mídia nem do público, criando um terreno favorável para que as empresas moldem as mentes dos decisores políticos sem a observação popular. Breve, os negócios tendem a ser mais influentes quando as matérias são apreciadas pelas comissões principais por tratarem, normalmente, de questões mais técnicas.

Sager, Bürki e Luginbühl (2014) investigaram como o programa de energia suíço "EnergieSchweiz" influenciou decisões políticas. O programa esteve vigente de 2000 a 2010 e envolvia diversas tarefas, várias delas foram atribuídas a organizações privadas, como, por exemplo, a Agência de Energia da Indústria (ENAW), que foi fundada em 1999 por diversas associações comerciais. Os seus objetivos eram notadamente reduzir o uso de combustiveis fósseis, diminuir as emissões de $\mathrm{CO}_{2}$ em $10 \%$ entre os anos de vigência do programa e garantir que o consumo total de eletricidade durante o mesmo período não aumentasse em mais de $5 \%$. A redução da emissão de $\mathrm{CO}_{2}$ teve como ponto central a criação de uma lei que introduzia um imposto sobre essa emissão, uma vez que medidas voluntárias de redução não surtiram efeitos em termos do alcance de metas. Segundo os autores, na implementação da Lei, o programa foi capaz de desencadear um efeito de aprendizagem no nível de conteúdo dos tomadores de decisão da administração pública e do parlamento e, ao fazê-lo, teve uma influência significativa sobre a introdução do imposto. No estudo fica claro que o impacto da influência do EnergieSchweiz foi devido a sua atuação nos debates parlamentares acerca do tema.

Sühlsen e Hisschemöller (2014) creditam às atividades de lobby do setor de energias renováveis a atual transição da política energética alemã. Os autores examinaram a influência das empresas de energias renováveis e concluíram que elas possuem uma forte interferência sobre a tomada de decisão política por utilizarem, em especial, estratégias que envolvem o contato próximo e frequente com os políticos; por fomentar o conhecimento dos mesmos com informações precisas sobre as matérias relativas ao tema; e por fazer um lobby conjunto em que são alinhados aos interesses de várias empresas.

Shelley, Ogedegbe e Elbel (2014) abordaram o programa de política pública da cidade de Nova lorque que previa a proibição de venda de bebidas adoçadas com açúcar acima de um certo limite. Uma decisão judicial derrubou a proibição e esta derrota do programa foi atribuída, em parte, à resistência da indústria de bebidas e de grupos de organizações de minorias raciais e étnicas. Os autores traçam um paralelo 
com a indústria de tabaco para comparar as situações parecidas de oposição de interesses empresariais frente aos interesses coletivos. Para isso, expuseram que esta indústria empregou estratégias como: a utilização de informações de pesquisas de mercado para melhorar a imagem de seus produtos; o uso da filantropia com organizações de representação de minorias, na intenção de neutralizar a oposição contra o tabagismo; e o recrutamento de influentes afro-americanos para comporem a força de trabalho da indústria do tabaco.

Assim, percebe-se que a indústria de bebidas ganhou o apoio das organizações de minorias raciais, pois os mesmos seriam os mais prejudicados uma vez que os comerciantes atingidos por essa política pública eram, em maior parte, os pertencentes a estas organizações. Ao mesmo tempo, por ser um programa da cidade de Nova lorque, os grandes comerciantes não seriam atingidos pelas determinações do programa, pois os mesmos são vinculados às determinações estaduais. Evidencia-se, então, a junção de grupos com interesses semelhantes na busca por alterações e ou mudanças em normas e legislações. Sobre a mesma ótica, Rasmussen (2015) e Bunea (2015) demostraram a importância da união de grupos para o atingimento de objetivos comuns.

Também Jones (2004) já havia abordado a relevância de se fazer a união de interesses comuns onde um grupo de enfermeiros buscou o apoio de grupos de médicos e farmacêuticos para persuadirem o governo em busca do atendimento de suas demandas.

Sobre a mesma abordagem, reforça-se que Jones (2004) trouxe o caso da influência política de um grupo de enfermeiros do Reino Unido que tinha por objetivo aprovar uma lei que conferisse o direito dos mesmos de poderem realizar a prescrição de medicamentos. 0 autor mostra que o grupo, para reforçar as atividades de lobby, percebe não apenas a necessidade de demonstrar os efeitos positivos que são gerados para os pacientes em termos de ganho de tempo, de melhoria de atendimento e de utilizarem pessoal especializado em conhecimentos legislativos para interferir no processo parlamentar, mas também a primordialidade de conquistar o apoio de grupos diretamente relacionados com as atividades dos enfermeiros, como o dos médicos e dos farmacêuticos. Jones (2004) ainda pontua que o caminho a ser seguido pelos enfermeiros é o de ir além de uma simples busca de apoio para os seus objetivos. É preciso agradar às exigências dos médicos e farmacêuticos e transformar estes potencias adversários em aliados fazendo-os enxergar que, nesta legislação, também existe algo positivo para eles. Percebe-se que esta atividade de criar aliança proveniente de objetivos comuns aproxima-se do que foi contemplado nos dizeres de Dummert (2013), em que explicita que para influenciar é necessário saber se posicionar estrategicamente em relação aos outros e compreender quais são os objetivos comuns existentes, para, no momento oportuno, transformar a influência em movimento da outra parte. 
Na tentativa de se compreender melhor como os interesses organizados obtêm resultados em textos legais e verificar a efetividade das ações de lobby sobre decisores públicos e parlamentares, dois estudos frisam a importância de se mensurar a influência dos grupos de interesses: Dür (2008) e Klüver (2009).

Dür (2008) versa que a análise da influência dos interesses organizados se apresenta como de fundamental importância para o entendimento dos processos políticos, bem como para que se obtenha explicações acerca dos resultados das pressões sobre as políticas. 0 autor salienta que a análise é dificultada pela existência de diferentes canais de influência, pela ocorrência de um lobbycontraproducente e pelo fato da influência ser aplicada em diversas fases do processo político. Para isso, Dür (2008) sugere três formas distintas de se medir a influência para que ela possa ser analisada mais precisamente: através de um processo de rastreamento, para descobrir os passos que afetam os resultados da influência dentro do processo legislativo; o método de influência atribuída, que geralmente é medido por meio de pesquisas em que um grupo solicita uma autoavaliação de sua influência ou uma avaliação por outros grupos. Além disso, pode ocorrer por meio de observadores que se reportam à reputação do grupo; e, por fim, o que o autor denomina de avaliar o grau de realização do grupo, que consiste em comparar os resultados obtidos pelas pressões nos processos políticos com os objetivos buscados naquilo que foi objeto de influência, a distância entre resultado e o objetivo almejado reflete o nivel de influência do grupo.

Klüver (2009) segue no sentido da importância de comparar as proposições políticas dos grupos de interesse com a saída política final para poder tirar conclusões sobre resultados exitosos ou não dos processos de pressões. Para isso, aborda o que foi exposto por Dür (2008) e acrescenta, em seu estudo, a importância da análise de conteúdo dos textos legais, pois, para ele, os dados textuais constituem a fonte que mais evidencia provas das marcas deixadas pelas atividades de pressão nos processos políticos. Ressalta, ainda, que os documentos políticos têm um grande potencial para revelar informações sobre as proposições políticas dos influenciadores.

Nada obstante, percebe-se que Dür (2008) e Klüver (2009) mostram a relevância de se mensurar o grau de realização dos objetivos oriundos das atividades que envolvem o lobby. Entrementes, como enfatiza Rufanges (2016), nem sempre os resultados são fáceis de serem verificados, uma vez que eles podem ser alcançados apenas no longo prazo. Evidencia-se que a mensuração é proveniente da necessidade de se enxergar a efetividade das atividades de influência política dos interesses organizados na consecução dos seus objetivos para se ter um feedback da importância de exercê-la. Isto entra na dimensão da estratégia dos negócios, pois, conforme assevera Marshall (2010), o custo de renunciar a participação em uma atividade de lobby é superior ao custo associado ao lobby de um rival do negócio. E mais, Scott (2015) salienta que o retorno sobre o investimento é considerável para empresas inteligentes 
o suficiente para investirem em atividades de lobby. Destaca que desenvolvê-las junto ao governo é uma tarefa bastante complexa, mas que pode ser refletida em retornos maciços; e frisa que um executivo se torna tolo e negligente ao deixar o jogo de influência para os próprios concorrentes.

\section{CONSIDERAÇõES FINAIS}

As investigações inicias sobre os temas que envolvem esta pesquisa resultou no estudo intitulado "A Percepção dos Parlamentares da Assembleia Legislativa do Rio Grande do Norte acerca do Lobby e do Poder de Influência dos Grupos de Pressão", e permitiu fazer entender e situar o pesquisador acerca da relevância dos mesmos e em que estágio se encontram os estudos e as publicações pertinentes a eles. A partir destas pesquisas preliminares, pode-se concluir, mesmo que antecipadamente, que a atividade de lobby se apresenta como fundamental para grupos que têm o anseio de defender interesses e de obter vantagens hipercompetitivas por intermédio de interferências no processo decisório público e na elaboração de legislações específicas. A concretização dos objetivos de grupos empresariais ou sociais tem dependido, conforme testemunhado nos estudos executados, de ações bem estruturadas de influência sobre parlamentares e autoridades públicas. Grupos que conseguem perceber e se adiantar na realização de atividades de lobby e de pressão e são perspicazes o suficiente para não deixar à mercê dos seus interesses ou dos concorrentes comerciais tais atividades, obtêm um ganho competitivo e garantem excelentes taxas de retorno sobre investimentos de toda ordem. Destaca-se que a efetividade da mensuração dos resultados depende do prévio planejamento das ações e da necessidade de comparação das propostas de alterações de matérias dos interesses organizados com o produto final alcançado.

Sumariando, este estudo preliminar permite observar que a atividade política de um parlamento está permeada de ações de influência e que entendê-las e usá-las em momentos adequados pode mudar a realidade dos negócios e mostrar um novo cenário de atuação para a consecução dos seus objetivos.

\section{LIMITAÇÕES DO ESTUDO}

Por se tratar de estudos preliminares, este artigo de discussão teórica se encontra limitado às ideias iniciais de um trabalho em curso, quer dizer, em fase de revisão do Estado da Arte sobre a atividade de influência proveniente do Lobby e dos Grupos de Pressão, aguardando a execução da segunda fase, a coleta de dados, a ser realizada por meio de múltiplas entrevistas junto ao parlamento do Estado do Rio Grande do Norte; a terceira fase, o tratamento dos dados, a ser efetuado com ou sem ajuda eletrônica; e, a última fase, o relato final. 


\section{REFERÊNCIAS}

ARAGÃO, M. Grupos de pressão no Congresso Nacional: como a sociedade pode defender licitamente seus direitos no poder legislativo. São Paulo: Maltese, 1994.

ARGYRIS, C. Savoir Pour Agir. Surmonter les obstacles à l'apprentissage organisationnel. Paris: InterEditions, 1995.

BARNES, K. B. Context, framing, and influence. Industrial and Commercial Training, v. 46, p. 73-76, 2014.

BEARD, R. The Pressure Groups. Education + Training, v. 11, n. 5, p. 172-173, 1969.

BECKER, G. S. A. Theory of Competition Among Pressure Groups for Political Influence. Quarterly Journal of Economics, v. 98, p. 371-400, 1983.

BUNEA, A. Sharing ties and preferences: Stakeholders' position alignments in the European Commission's open consultations. European Union Politics, v. 16, n. 2, p. 281-299, 2015.

CHALMERS, A. W. With a lot of help from their friends: Explaining the social logic of informational lobbying in the European Union. European Union Politics, v. 14, n. 4, p. 475-496, 2013.

CHONG, M. P. M.; FU, P. P.; SHANG, F. Y. Relational power and influence strategies: a step further in understanding power dynamics. Chinese Management Studies, v. 7, p. 53-73, 2013.

DUMMERT, M. The power of influence in health care Technology Management. 24x7, v. 18, n. 9, p. 42, 2013. Disponivel em: <http://go.galegroup. com/ps/i.do?p=AONE\&sw=w\&u=capes\&v=2.1\&it=r\&id=GALE\%7CA348999939\&asid=03796563b936c545209115669eb83d70 >. Acesso em: 28 jun. 2016.

DÜR, A. Forum Section Measuring Interest Group Influence in the EUA Note on Methodology. European Union Politics, v. 9, n. 4, p. 559-576, 2008.

EPSTEIN, G.; MEALEM, Y.; NITZAN, S. The efficacy and efforts of interest groups in post elections policy formation. Economics of Governance, v. 14, n. 1, p. 77-105, 2013.

FARHAT, S. LOBBY: o que é: como se faz. Ética e transparência na representação junto a governos. São Paulo: Peirópolis, ABERJE, 2007.

GRAZIANO, G. Lobbying, Troca e Definição de Interesses - Reflexões sobre o Caso Americano. DADOS Revista de Ciências Sociais, v. 37, n. 2, p. 317-340, 1994. 
GÜNEY, T. Environmental sustainability and pressure groups. Quality \& Quantity, v. 49, n. 6, p. 2331$2344,2015$.

HALL, R. L.; DEARDORFF, A. V. Lobbying as Legislative Subsidy. The American Political Science Review, v. 100, n. 1, p. 69-84, 2006.

JONES, M. Case Report. Nurse prescribing: a case study in policy influence. Journal of Nursing Management, v. 12, n. 4, p. 266-272, 2004.

KALKHOFF, W.; BARNUM, C. The Effects of Status-Organizing and Social Identity Processes on Patterns of Social Influence. Social Psychology Quarterly, v. 63, n. 2, p. 95-115, 2000.

KIPNIS, D.; SCHMIDT, S. M.; WILKINSON, I. C. Intraorganizational influence tactics: Explorations in gettingone's way. Journal of Applied Psychology, v. 65, n. 4, p. 440-452, 1980.

KLÜVER, H. Measuring Interest Group Influence Using Quantitative Text Analysis. European Union Politics, v. 10, n. 4, p. 535-549, 2009.

LIBARDI, F. F. Regulamentação do lobby no Brasil. Revista Jus Navigandi. n. 3117, 2012. Disponível em: <https://jus.com.br/artigos/20860>. Acesso em: 15 mai. 2016.

LOVAGLIA, M. J.; HOUSER, J. A. Emotional reactions and status in groups. American Sociological Review, v. 61, n. 5, p. 867-883, 1996.

LUCAS, J. W.; BAXTER, A. R. Power, Influence, and Diversity in Organizations. The ANNALS of the American Academy of Political and Social Science, v. 639, n. 1, p. 49-70, 2012.

MACK, R. Lobbying effectively in Brussels and Washington - Getting the right result. Journal of Communication Management, v. 9, n. 4, p. 339-347, 2005.

MACKLEY, G. Pressure groups have a right to lobby on assisted dying. Nursing Standard, v. 26, n. 6, p. 31. 2011. Disponivel em: <http://go.galegroup. com/ps/i.do?p=AONE\&sw=w\&u=capes\&v=2.1\&it=r\&id=GALE\%7CA271879672\&asid=afa5df4f3fcefd10bf768d7b6ab6b770.>. Acesso em: 25 jul. 2016.

MANNING, T. The art of successful influence: matching influence strategies and styles to the context. Industrial and Commercial Training, v. 44, n. 1, p. 26-34, $2012 \mathrm{a}$.

MANNING, T. The art of successful persuasion: seven skills you need to get your point across effectively. Industrial and Commercial Training, v. 44, n. 3, p. 150-158, 2012 b. 
MARSHALL, D. Who to lobby and when: Institutional determinants of interest group strategies in european parliament committees. European Union Politics, v. 11, n. 4, p. 553-575, 2010.

Explaining Interest Group Interactions with Party Group Members in the European Parliament: Dominant Party Groups and Coalition Formation. JCMS: Journal of Common Market Studies, v. 53, n. 2, p. 311-329, 2015.

MAYRHOFER, E. M. Lobbying the EU: the example of regional lobbies. Studia Europaea, v. 59, n. 1, p. 153-166, 2014.

MCKINNEY, B. ; HALPIN, D. Talking about Australian Pressure Groups: Adding Value to the Insider/Outsider Distinction in Combating Homelessness in Western Australia. Australian Journal of Public Administration, v. 66, n. 3, p. 342-352, 2007.

MEYER, C. B. When Radical Reforms Are on the Agenda. The Journal of Applied Behavioral Science, v. 48, n. 2, p. 194-224, 2012.

OLIVEIRA, A. C. J. LOBBYe Representação de Interesses: lobistas e seu impacto sobre a representação de interesses no Brasil, Tese de doutoramento, Universidade Estadual de Campinas, Campinas, 2004.

PARSONS, T. On the Concept of Influence. The Public Opinion Quarterly, v. 27, n. 1, p. 37-62, 1963.

POLERE, C. Lobbying: l'influence des groups d'intérêt s'accroît, et favorise une transformation de notre modèle démocratique. Le centre Ressources Perspectives dugrand Lyon, Lyon, 2007. Disponivel em: <http://www. millenaire3.com/content/download/1385/19395/version/1/file/lobbying.pdf. $>$. Acesso em: 21 jul. 2016.

RANA, K. Role of Pressure Groups in Indian Democracy, 2014. Disponivel em: <http:/www.importantindia.com/12257/role-of-pressure-groups-in-indian-democracy/.>. Acesso em: 25 jul. 2016.

RASMUSSEN, M. K. The Battle for Influence: The Politics of Business Lobbying in the European Parliament. JCMS: Journal of Common Market Studies, v. 53, n. 2, p. 365-382, 2015.

REBER, B. H.; BERGER, B. K. Finding influence: examining the role of influence in public relations practice. Journal of Communication Management, v. 10, p. 235-249, 2006.

RIVAI, M. Vers un lobbying ethique? Ou comment pratiquer l'inuence sans corruption. Entreprise

Ethique, Association Francophone de Comptabilité, v. 24, p. 20-27, 2006.

Are firms' lobbying strategies universal? Comparison of lobbying by French and UK firms. Journal of Strategy and Management, v. 5, n. 2, p. 211-230, 2012. 
ROMAGNI, P. O LOBBYing: viagem ao centro dos grupos de pressão e dos circuitos de influência: guia prático da arte de influenciar uma decisão. Lisboa: Dom Quixote, 1994.

RUFANGES, J. C. The Arms Industry Lobby in Europe. American Behavioral Scientist, v. 60, n. 3, p. 305320, 2016.

SAGER, F.; BÜRKI, M.; LUGINBÜHL, J. Can a policy program influence policy change? The case of the Swiss EnergieSchweiz program. Energy Policy, v. 74, p. 352-365, 2014.

SCOTT, C. D. Lobbying: a critical dimension of business strategy. International Journal of Law and Management, v. 57, n. 1, p. 17-27, 2015.

SELL, J.; LOVAGLIA, M. J.; MANNIX, E. A.; SAMUELSON, C. D.; WILSON, R. S. Investigating Confict, Power, and Status within and among Groups. Small Group Research, v. 35, n. 1, p. 44 - 72, 2004.

SHELLEY, D.; ELBEL, B.; OGEDEGBE, G. Same strategy different industry: corporate influence on public policy. The American Journal of Public Health, v. 104, n. 4, p. e9 - e11, 2014

SINHA, A. Pressure Group: role and function of pressure groups in India, 2012. Disponivel em: <http:// www.indiastudychannel.com/resources/152696-Pressure-Group-role-function.aspx.>. Acesso em: 25 jul. 2016.

SMITH, N. C. Pressure groups: a management introduction. Management Decision, v. 27, n. 5, p. 22-27, 1989.

SOIMU, S.; MARGARIT, A.; ANDRISAN, D. S.; STEFAN, I. Lobbying in the European Union: Practices and Challenges. EIRP Proceedings, v. 6, n. 1, p. 808-815, 2011.

SÜHLSEN, K.; HISSCHEMÖLLER, M. Lobbying the 'Energiewende'. Assessing the effectiveness of strategies to promote the renewable energy business in Germany. Energy Policy, v. 69, p. 316-325, 2014.

VASCONCELOS, C. R. M. L'Intelligence Economique et la Stratégie de Développement de la PME, 1999. Tese (Doutorado em Administração). Disponivel em: <http://penelope.upmf-grenoble.fr/cgi-bin/abnetclop?TITN=469540>.

WHAWELL, P. The Ethics of Pressure Groups Business Ethics. A European Review, v. 7, n. 3, p. 178-181, 1998.

WILLER, D.; LOVAGLIA, M. J.; MARKOVSKY, B. N. Power and influence: A theoretical bridge. Social Forces, v. 76, p. 571-603, 1997. 